\title{
Prognostic Significance of the C-Reactive Protein-to-Albumin Ratio in Patients With Metastatic Colorectal Cancer Treated With Trifluridine/Thymidine Phosphorylase Inhibitor as Later-line Chemotherapy
}

\author{
MASATSUNE SHIBUTANI ${ }^{1}$, HISASHI NAGAHARA ${ }^{1}$, TATSUNARI FUKUOKA $^{1}$, YASUHITO ISEKI $^{1}$, \\ SHINJI MATSUTANI ${ }^{1}$, EN WANG $^{1}$, KIYOSHI MAEDA ${ }^{1,2}$, KOSEI HIRAKAWA $^{1}$ and MASAICHI OHIRA ${ }^{1}$ \\ ${ }^{1}$ Department of Surgical Oncology, Osaka City University Graduate School of Medicine, Osaka, Japan; \\ ${ }^{2}$ Department of Gastroenterological Surgery, Osaka City General Hospital, Osaka, Japan
}

\begin{abstract}
Background/Aim: New drugs for metastatic colorectal cancer ( $m C R C$ ) have been recently developed for use in later-line chemotherapy and have contributed to further prolongation of the survival of patients. However, in later-line chemotherapy, treatment failure may lead to discontinuation of chemotherapy and the transition to best supportive care. Therefore, a biomarker able to predict the effects of later-line chemotherapy is required. The C-reactive protein-to-albumin ratio $(C A R)$, which is an inflammatory marker, has been reported to correlate with therapeutic outcome in patients with $m C R C$ who underwent first-line chemotherapy. However, the significance of the CAR as a marker for predicting the chemotherapeutic outcome in patients with $m C R C$ treated with later-line chemotherapy is unknown. Patients and Methods: We retrospectively reviewed the medical records of 40 patients with $m C R C$ who were treated with trifluridine/thymidine phosphorylase inhibitor (FTD/TPI) as a later-line chemotherapy. The CAR was calculated from the blood samples obtained within 1 week before the initiation of FTD/TPI by dividing the serum C-reactive protein level by the serum albumin level. Results: According to the receiver operating characteristic curve analysis, we set 0.122 as the CAR cut-off, and patients were classified into groups with high or low CAR. The low-CAR group had a significantly higher disease control rate than the high-CAR group. The progression-free and overall survival rates were significantly
\end{abstract}

Correspondence to: Masatsune Shibutani, Osaka City University Graduate School of Medicine, Department of Surgical Oncology, 14-3 Asahi-machi Abeno-ku, Osaka City, Osaka Prefecture, 5458585, Japan. Tel: +81 666453838, Fax: +81 666466450, e-mail: fbxbj429@ybb.ne.jp

Key Words: Colorectal cancer, chemotherapy, later-line, C-reactive protein-to-albumin ratio. better in the low-CAR group than in the high-CAR group. A high-CAR was associated with a greater number of prior regimens, higher serum lactate dehydrogenase level and more organs with metastases, considered to be correlated with the rate of disease progression. However, no significant differences were observed in the incidence of grade 3 or more adverse events, the relative dose intensity, or the rate of discontinuing chemotherapy between the two groups. Conclusion: The CAR may be a useful indicator for predicting the chemotherapeutic outcome in patients with $\mathrm{mCRC}$ treated with FTD/TPI as a late-line chemotherapy. The correlation between a high-CAR and poor prognosis was presumed to be due to the rate of cancer growth and increased resistance to chemotherapy rather than an insufficient dose of the drug.

Due to the development of new cytotoxic and moleculartargeted therapies, the prognosis of patients with metastatic colorectal cancer (mCRC) has improved, and the median overall survival time has been extended to approximately 30 months $(1,2)$. Furthermore, new drugs for use in later-line chemotherapy, such as trifluridine/thymidine phosphorylase inhibitor (FTD/TPI) and regorafenib, have recently been developed and have contributed to further prolongation of survival $(3,4)$. However, in later-line chemotherapy, treatment failure may lead to the discontinuation of chemotherapy and the transition to best supportive care. Therefore, the prediction of therapeutic outcome is required in later-line chemotherapy as well as in front-line chemotherapy.

Neutropenia caused by FTD/TPI was recently reported to be associated with better drug efficacy (5-7). However, the incidence of neutropenia becomes clear only after the initiation of chemotherapy. Therefore, a biomarker able to predict the effect of FTD/TPI before the start of treatment is required.

It has been reported that inflammation contributes to cancer progression and that inflammatory markers are associated with clinical outcomes in patients with various 
types of malignancies, including CRC (8-10). In our previous report, the C-reactive protein-to-albumin ratio (CAR), which is an inflammatory marker, was reported to correlate with therapeutic outcome in patients with $\mathrm{mCRC}$ who underwent first-line chemotherapy (11). However, there have been only a few reports on the prognostic value of inflammatory markers in patients with mCRC who undergo later-line chemotherapy (12). Therefore, the significance of these markers in later-line chemotherapy is unknown.

The aim of this study was to evaluate the significance of the CAR as a marker for predicting the chemotherapeutic outcome in patients with $\mathrm{mCRC}$ treated with FTD/TPI as a later-line chemotherapy.

\section{Patients and Methods}

Patients. We retrospectively reviewed the medical records of 40 patients with mCRC who were treated with FTD/TPI at the Osaka City University Hospital between June 2014 and January 2018. All patients had received at least two previous chemotherapeutic regimens. This retrospective study was approved by the Ethics Committee of the Osaka City University (approval number: 926) and conducted in accordance with the Declaration of Helsinki. All patients provided their written informed consent.

Methods. Pretreatment blood samples were obtained within 1 week before the initiation of FTD/TPI. The CAR was calculated from the blood samples by dividing the serum C-reactive protein level by the serum albumin level. An appropriate cut-off value of the CAR was determined according to receiver operating characteristic (ROC) curve analysis. The patients were then classified into groups with high or low CAR.

Response evaluations by computed tomography were performed every 8 weeks. Variation of approximately 2 weeks was regarded as allowable error. We adopted the Response Evaluation Criteria in Solid Tumors to classify the treatment response as follows (13): Complete response, partial response, stable disease and progressive disease. If the treatment was discontinued due to adverse events before the first response evaluation, the response was judged as not evaluable. If the treatment was discontinued due to the deterioration of the general condition caused by tumor burden, the response was judged as clinical progressive disease. An objective response was defined as a complete or partial response. Disease control was defined as a complete or partial response or stable disease. Adverse events were graded using Common Terminology Criteria for Adverse Events (Version 4.0). FTD/TPI treatment was continued until progression or unacceptable toxicity.

The lactate dehydrogenase (LDH) levels were measured using the blood samples obtained within 1 week before the initiation of FTP/TPI. Regarding RAS type GTPase family status, in some patients only KRAS proto-oncogene, GTPase (KRAS) was evaluated.

Statistical analyses. All statistical analyses were performed using the SPSS software package for Windows (SPSS, Chicago, IL, USA). The chi-square test, Fisher's exact test and Mann-Whitney's $U$-test were used to analyze the significance of correlations between the CAR and the clinicopathological characteristics/ chemotherapeutic response. Survival curves were estimated using the Kaplan-Meier

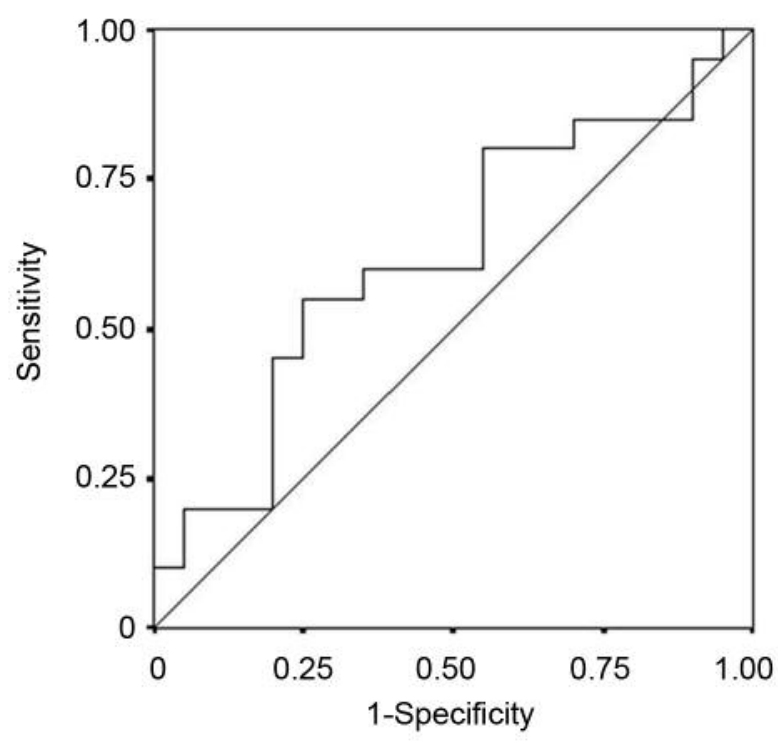

Figure 1. A receiver operating characteristic curve analysis of the $C$ reactive protein-to-albumin ratio $(C A R)$. Area under the curve $=0.620$, $95 \%$ confidence interval $=0.443-0.797, p=0.194$.

method, and the differences in the survival curves were assessed with the log-rank test. A multivariate analysis was performed using a Cox proportional hazards model. Statistical significance was set at a value of $p<0.05$.

\section{Results}

Classification according to the CAR. The CAR, as a continuous variable, was used as the test variable and the median survival time of 6.6 months as the state variable. Investigating the cut-off value for the CAR using ROC curve analysis, the appropriate cut-off value was found to be 0.122 (sensitivity=60.0\%; specificity $=65.0 \%$ ) (Figure 1 ). The cut-off value was therefore set at 0.122 and the 19 patients were classified into the highCAR group and 21 into the low-CAR group.

Correlations between the CAR and clinicopathological factors. The correlations between CAR pretreatment and the clinicopathological factors are shown in Table I. A high CAR was significantly associated with a greater number of prior regimens and higher serum $\mathrm{LDH}$ level, and tended to be associated with male gender and a greater number of organs with metastases.

Chemotherapeutic outcomes. The distribution of the chemotherapeutic response after FTD/TPI therapy with reference to the CAR subgroup is shown in Table II. The objective response rates did not differ markedly according to the CAR ( $4.8 \%$ vs. $0 \%, p=0.362)$. However, the low-CAR group had a significantly higher disease control rate than the 
Table I. Correlation between the C-reactive protein-to-albumin ratio $(C A R)$ and clinicopathological factors of patients with metastatic colorectal cancer.

\begin{tabular}{|c|c|c|c|}
\hline & \multicolumn{2}{|c|}{ CAR, $n$} & \multirow[b]{2}{*}{$p$-Value } \\
\hline & Low $(n=21)$ & High $(n=19)$ & \\
\hline \multicolumn{4}{|l|}{ Gender } \\
\hline Male & 10 & 15 & 0.055 \\
\hline Female & 11 & 4 & \\
\hline \multicolumn{4}{|l|}{ Age (years) } \\
\hline$<68$ & 10 & 11 & 0.545 \\
\hline$\geq 68$ & 11 & 8 & \\
\hline \multicolumn{4}{|c|}{ Location of the primary tumor } \\
\hline Right side & 8 & 3 & 0.163 \\
\hline Left side & 13 & 16 & \\
\hline \multicolumn{4}{|c|}{ The number of metastatic organs } \\
\hline 1 & 11 & 4 & 0.055 \\
\hline$\geq 2$ & 10 & 15 & \\
\hline \multicolumn{4}{|l|}{$R A S$ status } \\
\hline Wild-type & 7 & 12 & 0.103 \\
\hline Mutant & 13 & 6 & \\
\hline Unknown & 1 & 1 & \\
\hline \multicolumn{4}{|c|}{ Performance status } \\
\hline 0,1 & 19 & 15 & 0.398 \\
\hline$\geq 2$ & 2 & 4 & \\
\hline \multicolumn{4}{|c|}{ Number of prior regimens } \\
\hline$<4$ & 17 & 8 & 0.021 \\
\hline$\geq 4$ & 4 & 11 & \\
\hline \multicolumn{4}{|c|}{ Combined molecular-targeted therapy } \\
\hline None & 8 & 12 & 0.205 \\
\hline Bevacizumab & 13 & 7 & \\
\hline \multicolumn{4}{|c|}{ Serum LDH level (U/l) } \\
\hline$<300$ & 17 & 6 & 0.004 \\
\hline$\geq 300$ & 4 & 12 & \\
\hline
\end{tabular}

LDH: Lactate dehydrogenase; KRAS proto-oncogene, GTPase.

high-CAR group $(61.9 \%$ vs. $23.5 \%, p=0.025)$. The progression-free and overall survival rates were significantly better for the low-CAR group than for the high-CAR group ( $p=0.0055$ and $p=0.0004$, respectively) (Figures 2 and 3).

Prognostic factors influencing survival. The correlations between the progression-free survival and various clinicopathological factors are shown in Table III. According to the results of a univariate analysis, progression-free survival was significantly related to the number of organs affected by metastases, combined molecular-targeted therapy, serum LDH level and the CAR $(p<0.05)$, and tended to show a relationship with the location of the primary tumor $(p<0.1)$. A multivariate analysis indicated that the location of the primary tumor (left side) and combined moleculartargeted therapy were independent prognostic factors leading to better progression-free survival. The correlations between the overall survival and the various clinicopathological
Table II. Treatment response to chemotherapy of patients with metastatic colorectal cancer according to the C-reactive protein-toalbumin ratio $(C A R)$.

\begin{tabular}{lccr}
\hline & \multicolumn{2}{c}{ CAR } & \\
\cline { 2 - 3 } Response & Low (n=21) & High (n=19) & $p$-Value \\
\hline Complete response, $\mathrm{n}$ & 0 & 0 & \\
Partial response, $\mathrm{n}$ & 1 & 0 & \\
Stable disease, $\mathrm{n}$ & 12 & 4 & \\
Progressive disease, $\mathrm{n}$ & 8 & 13 & \\
Not evaluable, $\mathrm{n}$ & 0 & 2 & \\
\hline Objective response rate & $4.8 \%$ & $0 \%$ & 0.362 \\
Disease control rate & $61.9 \%$ & $23.5 \%$ & 0.025 \\
\hline
\end{tabular}

factors are shown in Table IV. According to the results of the univariate analysis, the overall survival showed significant relationships with combined molecular-targeted therapy and the CAR $(p<0.05)$ and tended to show a relationship with the performance status and serum LDH level $(p<0.1)$. A multivariate analysis indicated that the low CAR was an independent prognostic factor for better overall survival.

Correlations between the CAR and adverse events/ discontinuation of the treatment/relative dose intensity/ subsequent chemotherapy. No significant differences were observed in the incidence of grade 3 or more adverse events, relative dose intensity or rate of discontinuing treatment between the low-CAR group and the high-CAR group (Table $\mathrm{V})$. Furthermore, in the analysis limited to the patients who had discontinued FTD/TPI treatment and had not received regorafenib, no significant differences were observed regarding the transfer ratio of subsequent chemotherapy between the two groups (Table V).

\section{Discussion}

In this study, the CAR was found to be associated with chemotherapeutic outcome and survival in patients with mCRC treated with FTD/TPI as a later-line chemotherapy.

FTD suppresses tumor growth, and TPI maintains the serum concentration of FTD by preventing its rapid degradation $(14,15)$. As FTD/TPI exerts it effects by a mechanism different from 5-FU, it is effective against tumors resistant to 5-FU (16). FTD/TPI is used for patients with $\mathrm{mCRC}$ refractory to standard intensive chemotherapy as a later-line chemotherapy $(3,17)$. Although the incidence of grade 3 or more neutropenia has been reported to be as high as about $40 \%$, adverse events other than neutropenia are relatively mild (3). Therefore, FTD/TPI is an anticancer drug that is easy to manage, even for patients treated with 


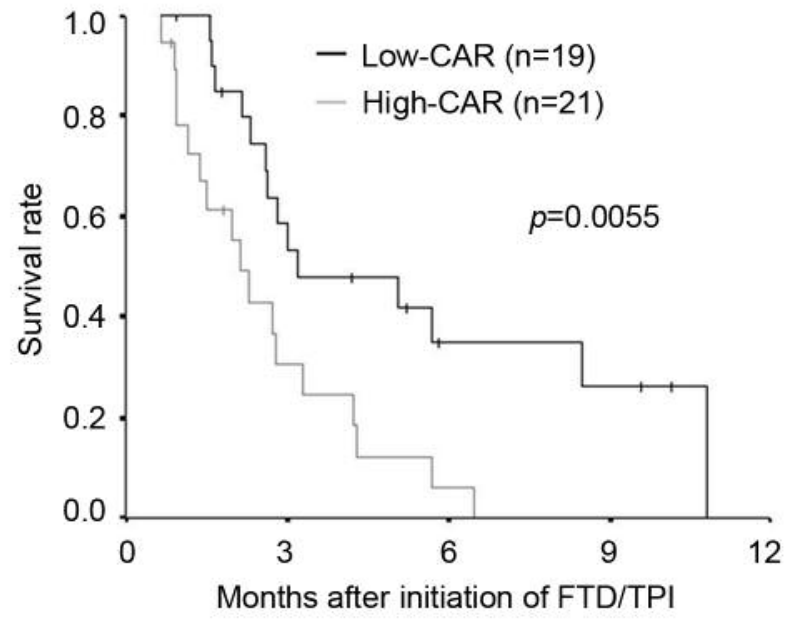

Figure 2. Kaplan-Meier curves for progression-free survival of patients with metastatic colorectal cancer according to C-reactive protein-toalbumin ratio (CAR) group. The progression-free survival rate was significantly worse for the group with a high CAR than for that with a low CAR ( $p=0.0055)$. FTD/TPI: Trifluridine/thymidine phosphorylase inhibitor

later-line chemotherapy who are prone to the deterioration of their condition. Although the effect of tumor shrinkage is not as ideal as with the anticancer drugs used in front-line chemotherapy, disease control is relatively good $(3,18)$. However, there are also some cases in which tumor growth cannot be suppressed, and the patient is judged to have progressive disease shortly after the initiation of later-line chemotherapy (3), as the tumor volume has already increased considerably in patients with $\mathrm{mCRC}$ who undergo later-line chemotherapy. These are issues that remain to be resolved in later-line chemotherapy.

In later-line chemotherapy, patients judged to have progressive disease often transition to best supportive care rather than subsequent chemotherapy. Therefore, predicting the therapeutic outcome is important in later-line chemotherapy as well as in front-line chemotherapy, although the significance may differ slightly.

As cancer progresses, inflammation and the production of cytokines both increase. These cytokines also promote cancer progression and metastasis (19-21). Therefore, inflammatory markers are thought to reflect the whole tumor volume and speed of disease progression. In the present study, the CAR was shown to be positively correlated with the number of organs with metastases, which is associated with the extent of cancer growth; the serum LDH level, which is associated with tumor aggressiveness reflecting hypoxia and angiogenesis (22); and the number of prior regimens, which is expected to be associated with the degree of disease progression. Furthermore, inflammation has also been reported to affect resistance to chemotherapy $(23,24)$. The CAR is an inflammatory marker

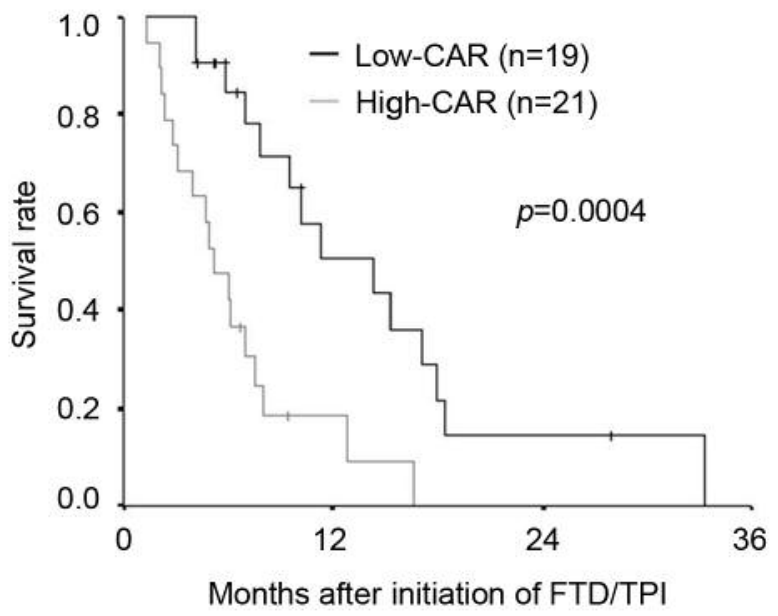

Figure 3. Kaplan-Meier curves for overall survival of patients with metastatic colorectal cancer according to $C$-reactive protein-to-albumin ratio (CAR) group. The overall survival rate was significantly worse for the group with a high CAR than for that with a low CAR $(p=0.0004)$. FTD/TPI: Trifluridine/thymidine phosphorylase inhibitor.

that is calculated from the serum $\mathrm{C}$-reactive protein and albumin levels. The CAR was initially investigated as a prognostic marker for patients with sepsis (25) and later applied as a marker for patients with malignancies (26). The CAR has been reported to correlate with the therapeutic outcomes of curative surgery and first-line chemotherapy in patients with various types of malignancies, including CRC $(11,27)$. Regarding the prognostic value, the CAR has been reported to be more accurate than the Glasgow prognostic score, although both values are calculated from the serum Creactive protein and albumin levels $(11,26)$.

Although there is no doubt that the ability of a drug to shrink a tumor is important, the condition of the patient, the degree of disease progression, and the tumor volume have greater influence on the prognosis of patients receiving laterline chemotherapy. Therefore, inflammatory markers, that reflect the status of the patient and the disease, are more useful as prognostic markers in cases of later-line chemotherapy than earlier.

We hypothesized that a high CAR was associated with a worse prognosis because patients with a high CAR might be expected to receive an insufficient dose of their drug due to their particularly poor condition. However, no significant differences were observed regarding the degree of dose reduction and the rate of discontinuation of the chemotherapy between the low-CAR group and the high-CAR group. Therefore, the correlation between a high-CAR and a poor prognosis was presumed to be due to the momentum of cancer growth and increased resistance to chemotherapy rather than an insufficient dose of the drug. 
Table III. Correlation between progression-free survival and various clinicopathological factors of patients with metastatic colorectal cancer.

\begin{tabular}{|c|c|c|c|c|c|c|c|}
\hline \multirow[b]{2}{*}{ Factor } & & \multicolumn{3}{|c|}{ Univariate analysis } & \multicolumn{3}{|c|}{ Multivariate analysis } \\
\hline & & Hazard ratio & $95 \% \mathrm{CI}$ & $p$-Value & Hazard ratio & $95 \% \mathrm{CI}$ & $p$-Value \\
\hline Age & $68 \geq v s .<68$ Years & 0.611 & $0.296-1.265$ & 0.185 & 0.462 & $0.189-1.131$ & 0.091 \\
\hline Gender & Female $v s$. male & 0.750 & $0.355-1.583$ & 0.450 & 0.975 & $0.286-3.321$ & 0.968 \\
\hline Performance status & $\geq 2 v s .<2$ & 1.929 & $0.782-4.760$ & 0.154 & 0.763 & $0.190-3.057$ & 0.702 \\
\hline Location of primary tumor & Right $v s$. left side & 2.119 & $0.904-4.969$ & 0.084 & 3.085 & $1.012-9.401$ & 0.048 \\
\hline Number of prior regimens & $\geq 4$ vs. $<4$ & 1.232 & $0.592-2.563$ & 0.577 & 0.690 & $0.200-2.373$ & 0.556 \\
\hline RAS status & Mutant $v s$. wild-type & 1.155 & $0.549-2.431$ & 0.705 & 1.768 & $0.608-5.146$ & 0.296 \\
\hline Organs affected by metastasis & $\geq 2 v s .1$ & 2.394 & $1.006-5.697$ & 0.048 & 2.384 & $0.641-8.8 .69$ & 0.195 \\
\hline Combined molecular-targeted therapy & Bevacizumab vs. none & 0.200 & $0.081-0.498$ & 0.001 & 0.173 & $0.058-0.514$ & 0.002 \\
\hline Serum LDH & $\geq 300 v s .<300 \mathrm{U} / 1$ & 2.256 & $1.055-4.825$ & 0.036 & 0.445 & $0.122-1.620$ & 0.219 \\
\hline CAR & $\geq 0.122$ vs. $<0.122$ & 2.750 & $1.303-5.807$ & 0.008 & 4.525 & $0.826-24.794$ & 0.082 \\
\hline
\end{tabular}

LDH: Lactate dehydrogenase; CAR: C-reactive protein-to-albumin ratio; CI, confidence interval; RAS: RAS type GTPase family status.

Table IV. Correlations between the overall survival and various clinicopathological factors.

\begin{tabular}{|c|c|c|c|c|c|c|c|}
\hline \multirow[b]{2}{*}{ Factor } & & \multicolumn{3}{|c|}{ Univariate analysis } & \multicolumn{3}{|c|}{ Multivariate analysis } \\
\hline & & Hazard ratio & $95 \% \mathrm{CI}$ & $p$-Value & Hazard ratio & $95 \% \mathrm{CI}$ & $p$-Value \\
\hline Age & $68 \geq v s .<68$ Years & 0.715 & $0.344-1.485$ & 0.368 & 0.644 & $0.278-1.491$ & 0.305 \\
\hline Gender & Female $v s$. male & 0.978 & $0.468-2.040$ & 0.952 & 1.854 & $0.609-5.645$ & 0.277 \\
\hline Performance status & $\geq 2 v s .<2$ & 2.323 & $0.924-5.842$ & 0.073 & 2.999 & $0.906-9.929$ & 0.072 \\
\hline Location of primary tumor & Right $v s$. left side & 1.602 & $0.610-4.206$ & 0.339 & 1.257 & $0.397-3.982$ & 0.697 \\
\hline Number of prior regimens & $\geq 4 v s .<4$ & 1.495 & $0.708-3.159$ & 0.292 & 1.319 & $0.456-3.811$ & 0.609 \\
\hline RAS status & Mutant $v s$. wild-type & 0.674 & $0.305-1.489$ & 0.329 & 1.296 & $0.457-3.676$ & 0.626 \\
\hline Organs affected by metastasis & $\geq 2$ vs. 1 & 1.805 & $0.852-3.826$ & 0.123 & 1.463 & $0.433-4.943$ & 0.540 \\
\hline Combined molecular-targeted therapy & Bevacizumab vs. none & 0.466 & $0.221-0.984$ & 0.045 & 0.565 & $0.229-1.393$ & 0.215 \\
\hline Serum LDH & $\geq 300$ vs. $<300 \mathrm{U} / 1$ & 1.879 & $0.903-3.911$ & 0.092 & 0.597 & $0.182-1.956$ & 0.395 \\
\hline CAR & $\geq 0.122$ vs. $<0.122$ & 3.923 & $1.749-8.802$ & 0.001 & 6.478 & $1.374-30.537$ & 0.018 \\
\hline
\end{tabular}

LDH: Lactate dehydrogenase; CAR: C-reactive protein-to-albumin ratio; CI, confidence interval; RAS: RAS type GTPase family status.

\section{Conclusion}

The CAR may be a useful indicator for predicting chemotherapeutic outcome in patients with $\mathrm{MCRC}$ who have been treated with FTD/TPI as a late-line chemotherapy and may be of great help when considering treatment strategies.

\section{Conflicts of Interest}

The Authors declare that they have no competing interests in regard to this study.

\section{Authors' Contributions}

MS designed the study, performed the statistical analysis and drafted the manuscript. HN, TF, YI, SM and EW collected the clinical data and critically revised the manuscript. $\mathrm{KM}, \mathrm{KH}$ and $\mathrm{MO}$ designed the study and critically reviewed the manuscript. All Authors read and approved the final manuscript.
Table V. Correlations between the C-reactive protein-to-albumin ratio $(C A R)$ and adverse events/discontinuation of the treatment/relative dose intensity/subsequent chemotherapy.

\begin{tabular}{|c|c|c|c|}
\hline \multirow[b]{2}{*}{ Factor } & \multicolumn{2}{|c|}{ CAR } & \multirow[b]{2}{*}{$p$-Value } \\
\hline & Low & High & \\
\hline \multicolumn{4}{|c|}{ Grade $\geq 3$ adverse events, $n$} \\
\hline No & 10 & 6 & \\
\hline Yes & 11 & 13 & 0.349 \\
\hline \multicolumn{4}{|c|}{ Relative dose intensity, $\%$} \\
\hline Median (range) & $86.0(50.0-100)$ & $80.0(50.0-100)$ & 0.846 \\
\hline \multicolumn{4}{|c|}{$\begin{array}{l}\text { Discontinuation due } \\
\text { to adverse events, } n\end{array}$} \\
\hline No & 18 & 16 & \\
\hline Yes & 3 & 3 & $>0.99$ \\
\hline \multicolumn{4}{|c|}{ Subsequent chemotherapy, $\mathrm{n}$} \\
\hline No & 5 & 4 & \\
\hline Yes & 10 & 14 & 0.697 \\
\hline
\end{tabular}




\section{References}

1 Heinemann V, von Weikersthal LF, Decker T, Kiani A, VehlingKaiser U, Al-Batran SE, Heintges T, Lerchenmüller C, Kahl C, Seipelt G, Kullmann F, Stauch M, Scheithauer W, Hielscher J, Scholz M, Müller S, Link H, Niederle N, Rost A, Höffkes HG, Moehler M, Lindig RU, Modest DP, Rossius L, Kirchner T, Jung A and Stintzing S: FOLFIRI plus cetuximab versus FOLFIRI plus bevacizumab as first-line treatment for patients with metastatic colorectal cancer (FIRE-3): A randomised, open-label, phase 3 trial. Lancet Oncol 15: 1065-1075, 2014. PMID: 28197787, DOI: $10.1007 /$ s00432-017-2344-3

2 Schwartzberg LS, Rivera F, Karthaus M, Fasola G, Canon JL, Hecht JR, Yu H, Oliner KS and Go WY: PEAK: a randomized, multicenter phase II study of panitumumab plus modified fluorouracil, leucovorin, and oxaliplatin (mFOLFOX6) or bevacizumab plus mFOLFOX6 in patients with previously untreated, unresectable, wild-type $K R A S$ exon 2 metastatic colorectal cancer. J Clin Oncol 32: 2240-2247, 2014. PMID: 24687833, DOI: 10.1200/JCO.2013.53.2473

3 Keramati AR, Fathzadeh M, Go GW, Singh R, Choi M, Faramarzi S, Mane S, Kasaei M, Sarajzadeh-Fard K, Hwa J, Kidd KK, Babaee Bigi MA, Malekzadeh R, Hosseinian A, Babaei M, Lifton RP and Mani A: A form of the metabolic syndrome associated with mutations in $D Y R K 1 B$. N Engl J Med 370: 1909-1919, 2014. PMID: 24827035, DOI: 10.1056/NEJMoa1301824

4 Grothey A, Van Cutsem E, Sobrero A, Siena S, Falcone A, Ychou M, Humblet Y, Bouché O, Mineur L, Barone C, Adenis A, Tabernero J, Yoshino T, Lenz HJ, Goldberg RM, Sargent DJ, Cihon F, Cupit L, Wagner A and Laurent D; CORRECT Study Group: Regorafenib monotherapy for previously treated metastatic colorectal cancer (CORRECT): an international, multicentre, randomised, placebo-controlled, phase 3 trial. Lancet 2013 381: 303-312, 2013. PMID: 23177514, DOI: 10.1016/S0140-6736(12)61900-X

5 Kasi PM, Kotani D, Cecchini M, Shitara K, Ohtsu A, Ramanathan RK, Hochster HS, Grothey A and Yoshino T: Chemotherapy induced neutropenia at 1-month mark is a predictor of overall survival in patients receiving TAS-102 for refractory metastatic colorectal cancer: a cohort study. BMC Cancer 16: 467, 2016. PMID: 27412464, DOI: 10.1186/s12885016-2491-y

6 Hamauchi S, Yamazaki K, Masuishi T, Kito Y, Komori A, Tsushima T, Narita Y, Todaka A, Ishihara M, Yokota T, Tanaka T, Machida N, Kadowaki S, Fukutomi A, Ura T, Onozawa Y, Ando M, Tajika M, Muro K, Yasui H, Mori K and Taniguchi H: Neutropenia as a predictive factor in metastatic colorectal cancer treated with TAS-102. Clin Colorectal Cancer 16: 51-57, 2017. PMID: 27522626, DOI: 10.1016/j.clcc.2016.07.005

7 Skuja E, Gerina-Berzina A, Hegmane A, Zvirbule Z, Vecvagare $E$ and Purkalne G: Duration of previous treatment as a prognostic factor in metastatic colorectal cancer treated with trifluridine/tipiracil. Mol Clin Oncol 8: 699-702, 2018. PMID: 29725539, DOI: $10.3892 / \mathrm{mco} .2018 .1600$

8 Shibutani M, Maeda K, Nagahara H, Noda E, Ohtani H, Nishiguchi $\mathrm{Y}$ and Hirakawa K: A high preoperative neutrophilto-lymphocyte ratio is associated with poor survival in patients with colorectal cancer. Anticancer Res 33: 3291-3294, 2013. PMID: 23898094, DOI: 10.3748/wjg.v21.i34.9966
9 Chua W, Charles KA, Baracos VE and Clarke SJ: Neutrophil/lymphocyte ratio predicts chemotherapy outcomes in patients with advanced colorectal cancer. Br J Cancer 104: 12881295, 2011. PMID: 21448173, DOI: 10.1038/bjc .2011 .100

10 Kishi Y, Kopetz S, Chun YS, Palavecino M, Abdalla EK and Vauthey JN: Blood neutrophil-to-lymphocyte ratio predicts survival in patients with colorectal liver metastases treated with systemic chemotherapy. Ann Surg Oncol 16: 614-622, 2009. PMID: 19130139, DOI: 10.1245/s10434-008-0267-6

11 Shibutani M, Maeda K, Nagahara H, Iseki Y, Hirakawa K and Ohira M: The significance of the C-reactive protein to albumin ratio as a marker for predicting survival and monitoring chemotherapeutic effectiveness in patients with unresectable metastatic colorectal cancer. Springerplus 5: 1798, 2016. PMID: 27812440, DOI: 10.1186/s40064-016-3529-y

12 Tsuchihashi K, Ito M, Moriwaki T, Fukuoka S, Taniguchi H, Takashima A, Kumekawa Y, Kajiwara T, Yamazaki K, Esaki T, Makiyama A, Denda T, Satake H, Suto T, Sugimoto N, Katsumata K, Ishikawa T, Kashiwada T, Oki E, Komatsu Y, Okuyama H, Sakai D, Ueno H, Tamura T, Yamashita K, Kishimoto J, Shimada Y and Baba E: Role of predictive value of the modified Glasgow Prognostic Score for later-line chemotherapy in patients with metastatic colorectal cancer. Clin Colorectal Cancer 17: e687-e697, 2018. PMID: 30149986, DOI: 10.1016/j.clcc.2018.07.004

13 Eisenhauer EA, Therasse P, Bogaerts J, Schwartz LH, Sargent D, Ford R, Dancey J, Arbuck S, Gwyther S, Mooney M, Rubinstein L, Shankar L, Dodd L, Kaplan R, Lacombe D and Verweij J: New Response Evaluation Criteria in Solid Tumours: revised RECIST guideline (version 1.1). Eur J Cancer 45: 228247, 2009. PMID: 19097774, DOI: 10.1016/j.ejca.2008.10.026

14 Fukushima M, Suzuki N, Emura T, Yano S, Kazuno H, Tada Y, Yamada Y and Asao T: Structure and activity of specific inhibitors of thymidine phosphorylase to potentiate the function of antitumor 2'-deoxyribonucleosides. Biochem Pharmacol 59: 1227-1236, 2000. PMID: 10736423, DOI: 10.1016/S00062952(00)00253-7

15 Tanaka N, Sakamoto K, Okabe H, Fujioka A, Yamamura K, Nakagawa F, Nagase H, Yokogawa T, Oguchi K, Ishida K, Osada A, Kazuno H, Yamada Y and Matsuo K: Repeated oral dosing of TAS-102 confers high trifluridine incorporation into DNA and sustained antitumor activity in mouse models. Oncol Rep 32: 2319-2326, 2014. PMID: 25230742, DOI: 10.3892/or.2014.3487

16 Emura T, Suzuki N, Yamaguchi M, Ohshimo $\mathrm{H}$ and Fukushima M: A novel combination antimetabolite, TAS-102, exhibits antitumor activity in FU-resistant human cancer cells through a mechanism involving FTD incorporation in DNA. Int J Oncol 25: 571-578, 2004. PMID: 15289858, DOI: 10.3892/ijo.25.3.571

17 Moriwaki T, Fukuoka S, Taniguchi H, Takashima A, Kumekawa Y, Kajiwara T, Yamazaki K, Esaki T, Makiyama C, Denda T, Satake H, Suto T, Sugimoto N, Enomoto M, Ishikawa T, Kashiwada T, Sugiyama M, Komatsu Y, Okuyama H, Baba E, Sakai D, Watanabe T, Tamura T, Yamashita K, Gosho M and Shimada Y: Propensity score analysis of regorafenib versus trifluridine/tipiracil in patients with metastatic colorectal cancer refractory to standard chemotherapy (REGOTAS): A Japanese Society for Cancer of the Colon and Rectum Multicenter Observational Study. Oncologist 23: 7-15, 2018. PMID: 28894015, DOI: 10.1634/theoncologist.2017-0275. 
18 Yoshino T, Mizunuma N, Yamazaki K, Nishina T, Komatsu Y, Baba H, Tsuji A, Yamaguchi K, Muro K, Sugimoto N, Tsuji Y, Moriwaki T, Esaki T, Hamada C, Tanase T and Ohtsu A: TAS102 monotherapy for pretreated metastatic colorectal cancer: a double-blind, randomised, placebo-controlled phase 2 trial. Lancet Oncol 13: 993-1001, 2012. PMID: 22951287, DOI: $10.1016 /$ S1470-2045(12)70345-5

19 Coussens LM and Werb Z: Inflammation and cancer. Nature 420: 860-867, 2002. PMID: 12490959, DOI: 10.1038/ nature 01322

20 Mantovani A, Allavena P, Sica A and Balkwill F: Cancer-related inflammation. Nature 454: 436-444, 2008. PMID: 18650914, DOI: $10.1038 /$ nature 07205

21 Chiang AC and Massagué J: Molecular basis of metastasis. N Engl J Med 359: 2814-2823, 2008. PMID: 19109576, DOI: 10.1056/NEJMra0805239.

22 Faloppi L, Scartozzi M, Bianconi M, Svegliati Baroni G, Toniutto P, Giampieri R, Del Prete M, De Minicis S, Bitetto D, Loretelli C, D'Anzeo M, Benedetti A and Cascinu S: The role of LDH serum levels in predicting global outcome in HCC patients treated with sorafenib: Implications for clinical management. BMC Cancer 14: 110, 2014. PMID: 24552144, DOI: $10.1186 / 1471-2407-14-110$

23 Colotta F, Allavena P, Sica A, Garlanda C and Mantovani A: Cancer-related inflammation, the seventh hallmark of cancer: Links to genetic instability. Carcinogenesis 30: 1073-1081, 2009. PMID: 19468060, DOI: 10.1093/carcin/bgp127
24 Kumari N, Dwarakanath BS, Das A and Bhatt AN: Role of interleukin-6 in cancer progression and therapeutic resistance. Tumour Biol 37: 11553-11572, 2016. PMID: 27260630, DOI: 10.1007/s 13277-016-5098-7

25 Ranzani OT, Zampieri FG, Forte DN, Azevedo LC and Park M: C-reactive protein/albumin ratio predicts 90-day mortality of septic patients. PLoS One 8: e59321, 2013. PMID: 23555017, DOI: 10.1371 /journal.pone.0059321

26 Kinoshita A, Onoda H, Imai N, Iwaku A, Oishi M, Tanaka K, Fushiya N, Koike K, Nishino $\mathrm{H}$ and Matsushima M: The Creactive protein/albumin ratio, a novel inflammation-based prognostic score, predicts outcomes in patients with hepatocellular carcinoma. Ann Surg Oncol 22: 803-810, 2015. PMID: 25190127, DOI: 10.1245/s10434-014-4048-0

27 Shibutani M, Maeda K, Nagahara H, Iseki Y, Ikeya T and Hirakawa K: Prognostic Significance of the preoperative ratio of C-reactive protein to albumin in patients with colorectal cancer. Anticancer Res 36: 995-1001, 2016. PMID: 26976989

Received December 30, 2018

Revised January 19, 2019

Accepted January 21, 2019 